\title{
Caffeine Intake from Coffee or Tea and Cognitive Disorders: A Meta-Analysis of Observational Studies
}

\author{
Young-Seok Kim ${ }^{\mathrm{a}}$ Sang Mi Kwak ${ }^{\mathrm{b}}$ Seung-Kwon Myung ${ }^{\mathrm{c}-\mathrm{e}}$ \\ ${ }^{a}$ Seoul National University Hospital, Seoul, b Health Screening Center, Kangbuk Samsung Hospital, Sungkyunkwan \\ University, School of Medicine, Seoul, ' Molecular Epidemiological Branch, Research Institute, National Cancer \\ Center, Goyang, dDepartment of Family Medicine, Hospital, National Cancer Center, Goyang, ${ }^{e}$ Center for Cancer \\ Prevention and Detection, Hospital, National Cancer Center, Goyang, Republic of Korea
}

\author{
Key Words \\ Caffeine - Coffee - Tea - Cognitive disorders - Dementia . \\ Alzheimer's disease $\cdot$ Cognitive impairment $\cdot$ Cognitive \\ decline $\cdot$ Meta-analysis
}

\begin{abstract}
Background: Observational epidemiological studies such as cross-sectional, case-control, and cohort studies have reported inconsistent findings regarding the association between caffeine intake from coffee or tea and the risk of cognitive disorders such as dementia, Alzheimer's disease, cognitive impairment, and cognitive decline. Methods: We searched PubMed and EMBASE in September 2014. Three evaluators independently extracted and reviewed articles, based on predetermined selection criteria. Results: Out of 293 articles identified through the search and bibliographies of relevant articles, 20 epidemiological studies from 19 articles, which involved 31,479 participants $(8,398$ in six crosssectional studies, 4,601 in five case-control studies, and 19,918 in nine cohort studies), were included in the final analysis. The pooled odds ratio (OR) or relative risk (RR) of caffeine intake from coffee or tea for cognitive disorders (dementia, Alzheimer's disease, cognitive impairment, and cognitive decline) was 0.82 (95\% confidence interval [Cl], 0.67-
\end{abstract}

$\left.1.01, I^{2}=63.2 \%\right)$ in a random-effects meta-analysis. In the subgroup meta-analysis by caffeine sources, the summary OR or RR of coffee intake was $0.83\left(95 \% \mathrm{Cl}, 0.70-0.98 ; \mathrm{l}^{2}=\right.$ $44.8 \%)$. However, in the subgroup meta-analysis by study design, the summary estimates (RR or OR) of coffee intake for cognitive disorders were $0.70\left(95 \% \mathrm{Cl}, 0.50-0.98 ; \mathrm{I}^{2}=42.0 \%\right)$ for cross-sectional studies, $0.82\left(95 \% \mathrm{Cl}, 0.55-1.24 ; I^{2}=33.4 \%\right)$ for case-control studies, and $0.90\left(95 \% \mathrm{Cl}, 0.59-1.36 ; \mathrm{I}^{2}=\right.$ $60.0 \%$ ) for cohort studies. Conclusions: This meta-analysis found that caffeine intake from coffee or tea was not associated with the risk of cognitive disorders.

(C) 2015 S. Karger AG, Basel

\section{Introduction}

Dementia is a clinical syndrome characterized by multiple cognitive deficits such as deterioration in memory, language, thinking, and behavior severe enough to interfere with daily activities. According to a recent survey, dementia is the second leading health concern among adults following cancer [1]. Dementia is an age-

Y.-S.K. and S.M.K. equally contributed to this paper as first author.

\section{KARGER 125}

() 2015 S. Karger AG, Base

0251-5350/15/0441-0051\$39.50/0

E-Mail karger@karger.com

www.karger.com/ned
Seung-Kwon Myung, MD, PhD

Center for Cancer Prevention \& Detection, Hospital

National Cancer Center, 323 Ilsan-ro, Ilsandong-gu

Goyang, Gyeonggi-do 410-769 (Republic of Korea)

E-Mailmsk@ncc.re.kr 
related neurodegenerative disease, mainly developing in people over 65 years. The two most common forms of dementia are Alzheimer's disease (AD) and vascular dementia. Cognitive disorders such as dementia, cognitive impairment, and cognitive decline are known to be caused by complex interactions of genetic factors and environmental factors such as dietary habits, psychosocial activities, educational levels, and various medical diseases [2]. Because the pharmacologic treatments are limited, clinicians have paid attention to modifiable risk factors such as hypertension, dyslipidemia, diabetes mellitus, obesity, and lifestyle to prevent or delay the onset of cognitive disorders $[2,3]$. Regarding lifestyle factors, it has been reported that smoking [4], moderate wine consumption [2], lack of exercise [2, 5], and some nutrients (food or supplements) $[3,6]$ are associated with the risk of cognitive disorders. Recently, the potential effect of caffeine on brain function has become an important issue.

Caffeine is found in numerous foods and beverage items such as coffee, tea, soft drinks, chocolates, and candy bars. Among those, coffee and tea are the leading dietary sources of caffeine. [7]. Caffeine mainly acts upon the central nervous system, increasing arousal and concentration and decreasing fatigue [7]. Although its longterm effects are not yet fully understood, a number of animal studies have suggested that caffeine has neuroprotective effects [8-10]. Regarding the biological effect of caffeine, it acts as a nonselective $\mathrm{A}_{1}$ and $\mathrm{A}_{2 \mathrm{~A}}$ adenosine receptor antagonist and stimulates cholinergic neurons. A blockade of $A_{2 A}$ receptors is likely to have a neuroprotective effect from amyloid- $\beta$-induced cognitive deficits [10]. As proof of this hypothesis, caffeine intake lowered brain amyloid- $\beta$ levels in AD-transgenic mice [8]. As for the association between caffeine and cognitive disorders in general populations, epidemiological studies [11-25] such as cross-sectional studies, case-control studies, and cohort studies have reported inconsistent findings. Some studies have suggested that caffeine intake from coffee or tea is inversely associated with the risk of $\mathrm{AD}$, cognitive impairment, or cognitive decline. However, other studies have reported no association.

Several systematic reviews [26-28] and meta-analyses $[26,29,30]$ on this issue have been reported. In 2010, a meta-analysis of 11 observational studies [30] suggested that caffeine intake is marginally associated with a decreased risk of cognitive impairment or decline with a summary relative risk (RR) of 0.84 (95\% confidence interval [CI], 0.72-0.99, $\left.\mathrm{I}^{2}=42.6 \%\right)$. However, it included only coffee as caffeine sources and used only the most precise (i.e., the narrowest 95\% CIs) ORs or RRs among the results of the included studies, regardless of the exposure sources, levels of exposure, and outcomes assessed, which might cause biases.

In this study, we aimed to investigate the association between caffeine intake from coffee or tea and the risk of cognitive disorders such as dementia, $\mathrm{AD}$, cognitive impairment, and cognitive decline by using meta-analysis of the recently published epidemiological studies with subgroup meta-analysis by various factors.

\section{Methods}

Literature Search

We searched PubMed and EMBASE from inception to September 2014 using keywords related to caffeine and cognitive disorders. The keywords were as follows: 'coffee,' 'caffeine,' or 'tea' and 'dementia,' 'Alzheimer Disease,' 'mild cognitive impairment (MCI),' or 'cognitive decline'. We also reviewed the bibliographies of relevant articles for additional publications. The language of publications was restricted to English.

\section{Selection Criteria}

We selected observational epidemiologic studies reporting the relationships between caffeine consumption from coffee or tea intake (not caffeine-containing pill supplements) and cognitive disorders such as $\mathrm{AD}$, cognitive impairment, and cognitive decline in human adults by using adjusted relative risks (RRs) or odds ratios (ORs) with confidence intervals (CIs). We included cross-sectional, case-control, and cohort studies.

For the articles selected from the first selection process based on the predetermined criteria, we reviewed the full text and then excluded studies with insufficient data or irrelevant ones. If data were duplicated or shared in more than one study, the first published or more comprehensive study was included in the analysis. Three of us (Y.-S.K., S.M.K., and S.-K.M.) independently evaluated the eligibility of all studies retrieved from the databases according to the selection criteria. Disagreements between evaluators were resolved by discussion.

\section{Data Synthesis and Meta-Analysis}

We investigated the association between caffeine intake (highest vs. lowest intake) and the risk of cognitive disorders as a main analysis. In the current study, main outcome measures were classified into four categories (dementia, $\mathrm{AD}$, cognitive impairment, and cognitive decline). If a study reported both coffee and tea intake rather than caffeine intake, coffee was chosen as a surrogate marker because the amount of caffeine in coffee is probably at least two times higher than in tea $[12,21,24]$.

In addition, we performed subgroup meta-analyses based on the following factors: study design (cross-sectional vs. case-control vs. cohort), caffeine source (coffee vs. tea), type of outcome (dementia vs. $\mathrm{AD}$ vs. cognitive impairment vs. cognitive decline), race of participants (Asian vs. Caucasian), gender (male vs. female), methodological quality of the study (high vs. low), dosage of caffeine intake (lowest vs. moderate vs. highest), and frequency of caffeine intake (daily vs. not daily) by type of caffeine source. 
Fig. 1. Flow diagram of identification of Identified studies from the data bases using the keywords and the bibliographies of relevant articles $(n=293)$ :

Pub Med $(n=134)$, EMBASE $(n=155)$, and bibliographies $(n=4)$

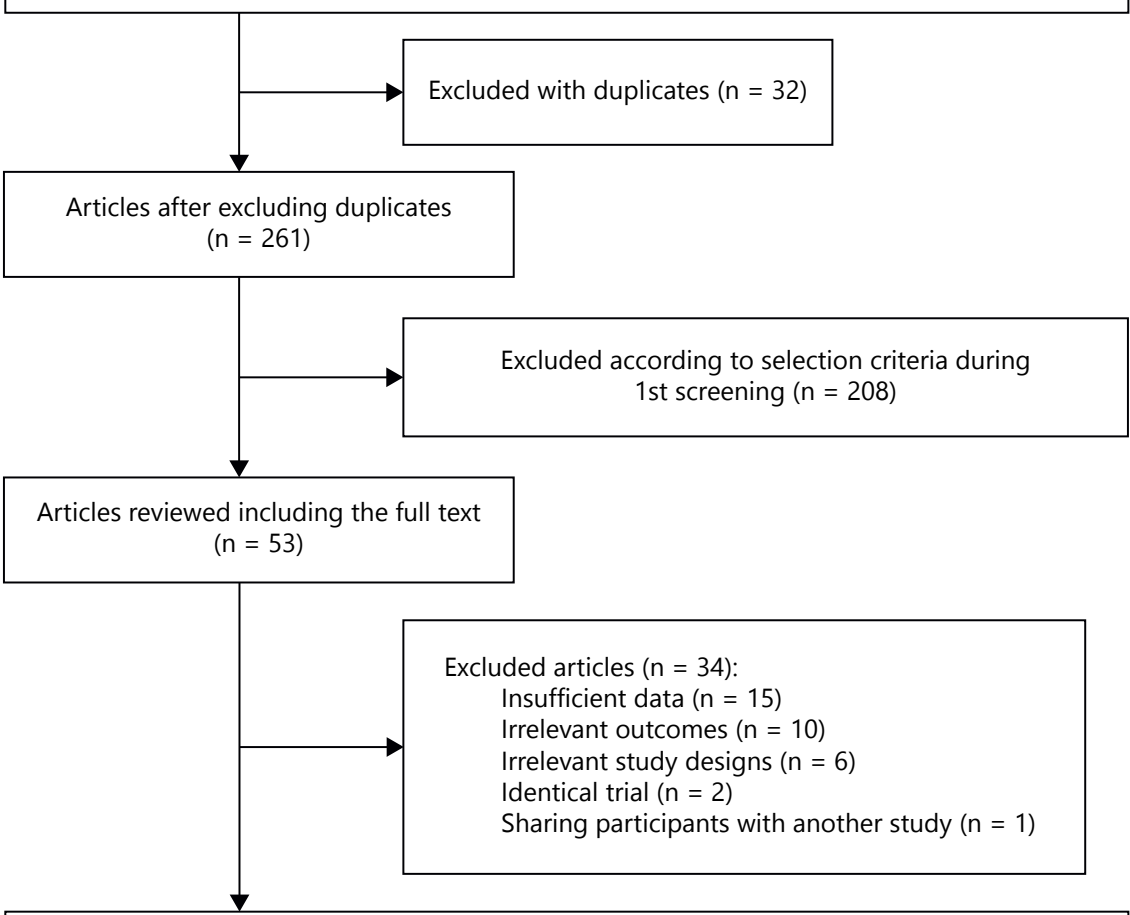

19 articles with 20 studies included in the final analysis: cross-sectional study $(n=6)$, case-control study $(n=5)$, and cohort study $(n=9)$ relevant studies.

\section{Assessment of Methodological Quality}

We assessed the methodological quality of 14 studies (five casecontrol and nine cohort studies) based on the Newcastle-Ottawa Scale (NOS) for nonrandomized studies in meta-analysis [31]. The NOS comprises 8 items with 3 subscales: the selection of the study groups (4 items), the comparability of the groups ( 1 item), and the ascertainment of either the exposure or outcome of interest for case-control or cohort studies respectively (3 items). It has a 'star' system, which ranges 0 to 9 stars for the assessment: each study is awarded a maximum of 1 star for each numbered item within the selection and exposure categories, while a maximum of 2 stars can be given for the comparability category. Also, subgroup analyses by study quality were performed.

\section{Statistical Analysis}

To compute a pooled OR/RR with a $95 \%$ CI, we used an adjusted OR/RR with a 95\% CI presented in each article. We evaluated heterogeneity in results across studies using Higgins $\mathrm{I}^{2}$ [32]. $\mathrm{I}^{2}$ ranges between $0 \%$ (no heterogeneity) and $100 \%$ (maximal heterogeneity). An $\mathrm{I}^{2}$ value $>50 \%$ was considered having substantial heterogeneity.

The pooled OR/RR with $95 \% \mathrm{CI}$ was calculated on the basis of both the fixed- and random-effects models. When there was no substantial heterogeneity, we reported the pooled estimates calcu- lated based on the fixed-effects model using the Woolf's method (inverse variance); when there was substantial heterogeneity, we reported the pooled estimates calculated based on the randomeffects model using the DerSimonian and Laird method.

Publication bias was evaluated by using a Begg's funnel plot and an Egger's test [33,34]. Funnel plots are scatter plots of the log odds ratios or log relative risks (i.e., effect sizes) on the $\mathrm{X}$-axis against the sample sizes (or standard errors or 1/standard error; a measure of precision) of each studies on the $\mathrm{Y}$-axis. If publication bias is absent, the log odds ratios or log relative risks of small studies scatter widely at the bottom of the graph, with the spread narrowing among large studies, and the Begg's funnel plot will show a symmetrical inverted funnel. If publication bias exists, the plot is asymmetrical or the $p$ value is less than 0.05 by the Egger's test. We used Stata SE version 10.0 software package (StataCorp, College Station, Texas, USA) for the statistical analysis.

\section{Results}

Figure 1 shows a flow diagram for identifying relevant studies. A total of 293 articles were searched from two databases and hand-searching relevant bibliographies. 
We excluded 32 duplicate articles and additional 208 articles not satisfying the selection criteria. We reviewed the full texts of the remaining 53 articles. Among them, 34 articles were excluded because of insufficient data ( $\mathrm{n}=$ $15)$, irrelevant outcomes $(n=10)$, irrelevant study design $(n=6)$, identical trial $(n=2)$, and sharing participants with another study $(\mathrm{n}=1)$. The remaining 20 studies (six cross-sectional studies, fiver case-control studies, and nine cohort studies) from 19 articles [11-25, 35-38] were included in the final analysis.

\section{Study Characteristics}

Table 1 summarizes the general characteristics of the 20 studies included in the final analysis. A total of 31,479 participants $(8,398$ in six cross-sectional studies, 4,601 in five case-control studies, and 19,918 in nine cohort studies) were included in the analysis. For studies reporting age and sex at the time of the enrollment period, the mean age of the study participants was 71.9 (range, 45 to 108 years), and $51.8 \%$ of them were women. The included studies were published from 1990 to 2014, spanning 24 years and were performed in the following countries: China $(\mathrm{n}=3)[12,13,38]$, Finland $(\mathrm{n}=2)[23,24]$, Portugal $(\mathrm{n}=2)[18,25]$, USA $(\mathrm{n}=3)[19,21,35]$, Australia $(\mathrm{n}=$ 1) [16], Canada $(n=1)$ [20], France $(n=1)$ [22], Norway $(\mathrm{n}=1)$ [14], Taiwan $(\mathrm{n}=1)$ [15], England $(\mathrm{n}=1)$ [17], Japan $(\mathrm{n}=2)$ [11, 37], and Jordan $(\mathrm{n}=1)$ [36]. In cohort studies, follow-up periods ranged between 1.3 years and 28 years (mean, 8.4 years), and the completeness of followup ranged from 58.2 to $98.2 \%$ (mean, $75.8 \%$ ). Regarding caffeine sources, five studies $[18,19,22,25,35]$ presented an estimated amount of caffeine intake; eight studies [11, $12,15,16,20,23,36,37]$ presented both coffee and tea intake; five studies $[13,14,17,21,38]$ presented only tea intake; and one study [24] presented only coffee intake. Highest categories of caffeine intake in each study ranged from more than 3 times per week to 8 cups per day as coffee units. Meanwhile, reference categories ranged from never or rare intake to 3 cups per day as coffee units.

Regarding diagnostic criteria of study outcomes, the included studies used DSM-IV [39] or TELE [40] for dementia, NINCDS-ADRDA [41] for AD, MMSE [42] for cognitive decline or cognitive impairment.

According to the quality assessment by the NOS, the mean value for the 14 case-control and cohort studies was 6.8 stars. In the current study, we considered a study awarded $\geq 7$ stars as a high-quality study because the criteria for high quality have not been established. Among all the included studies assessed, eight studies [16, 18-22, $25,38]$ were identified as having a high-quality (table 2 ).

\section{Association of Caffeine Intake and Risk of}

\section{Dementia}

As shown in figure 2, caffeine intake was not significantly associated with the risk of cognitive disorders including dementia, $\mathrm{AD}$, cognitive impairment, and cognitive decline in the random-effects meta-analysis of all 19 studies (OR/RR, 0.82; 95\% CI, 0.67-1.01; $\mathrm{I}^{2}=63.2$ ). In the subgroup meta-analysis by outcome, effect sizes (OR/RR with 95\% CI) of caffeine intake were $0.72(0.34-1.51)$ for dementia, $0.78(0.50-1.22)$ for $\mathrm{AD}, 0.79(0.61-1.04)$ for cognitive impairment, and $0.99(0.70-1.39)$ for cognitive decline. No publication bias was observed in the included studies (Begg's funnel plot, symmetrical; Egger's test, $p$ for bias $=0.63)$ (fig. 3).

\section{Subgroup Meta-Analyses}

Table 3 shows findings from the subgroup meta-analyses by various factors. Regarding the type of caffeine sources, the summary estimate for the association between coffee intake and cognitive disorders was 0.83 (95\% CI, 0.70-0.98), with moderate heterogeneity $\left(\mathrm{I}^{2}=\right.$ $44.8 \%)$. However, in subgroup meta-analysis by study design, the summary estimates (RR or OR) of coffee intake for cognitive disorders were 0.70 (95\% CI, 0.50 $\left.0.98 ; \mathrm{I}^{2}=42.0 \%\right)$ for cross-sectional study, 0.82 (95\% CI, $\left.0.55-1.24 ; \mathrm{I}^{2}=33.4 \%\right)$ for case-control study, and 0.90 (95\% CI, 0.59-1.36; $\mathrm{I}^{2}=60.0 \%$ ) for cohort study. Also, no other significant association was observed in the remaining subgroup meta-analyses by the following factors: tea consumption, study design (cross-sectional vs. case-control vs. cohort), type of outcome (dementia vs. $\mathrm{AD}$ vs. cognitive impairment vs. cognitive decline), race of participants (Asian vs. Caucasian), gender (male vs. female), methodological quality ( $\geq 7$ vs. $<7$ ), dosage of caffeine intake (lowest vs. moderate vs. highest), and caffeine intake whether daily or occasionally (coffee vs. tea).

\section{Discussion}

The current meta-analysis found that there was no association between caffeine intake from coffee or tea and the risk of cognitive disorders such as dementia, $\mathrm{AD}, \operatorname{cog}$ nitive impairment, and cognitive decline. Coffee intake was associated with a decreased risk of cognitive disorders in the meta-analysis of all the observational studies including cross-sectional, case-control, and cohort studies. However, in the subgroup meta-analysis of cohort studies, its preventive effect was not shown.
Kim/Kwak/Myung 


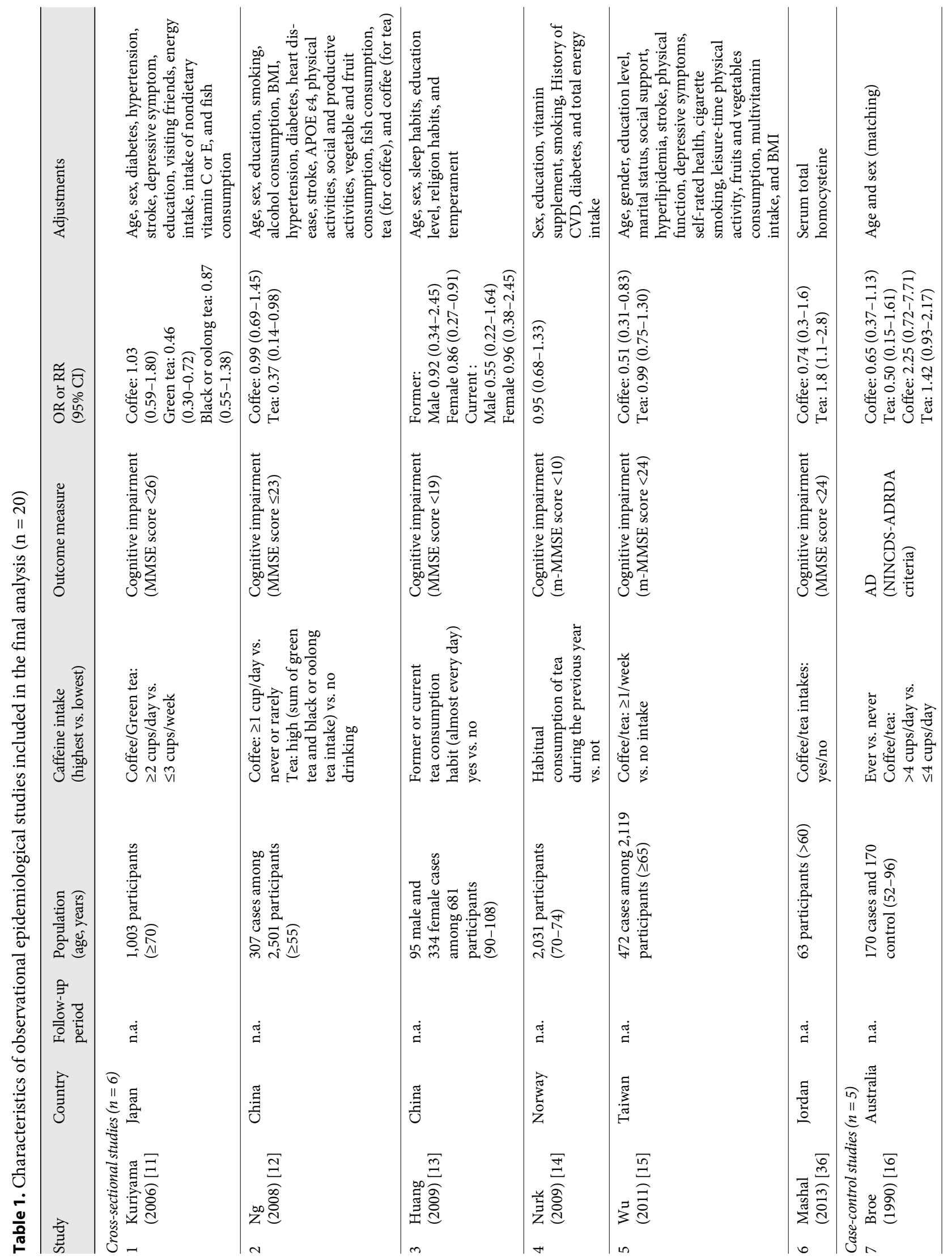




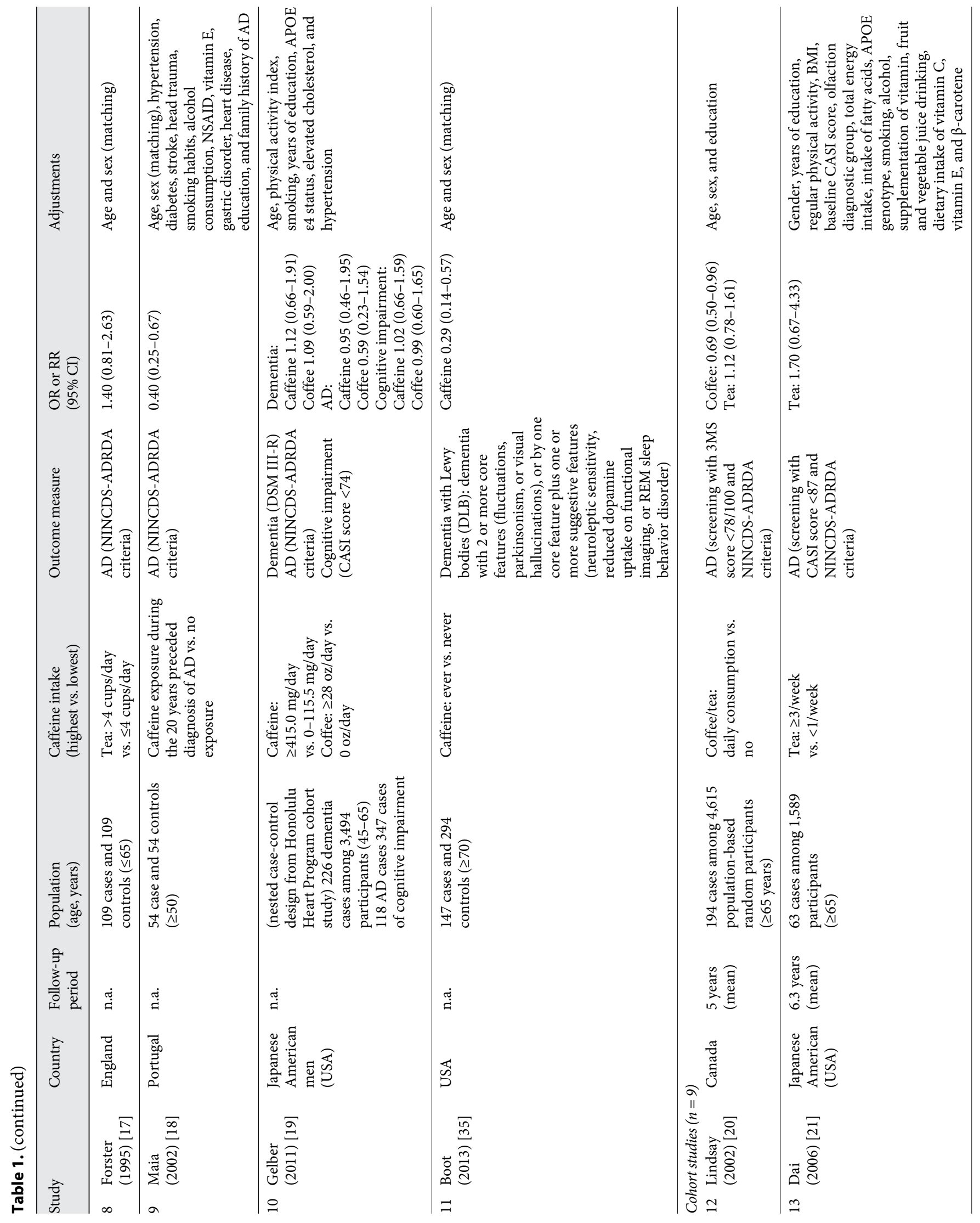




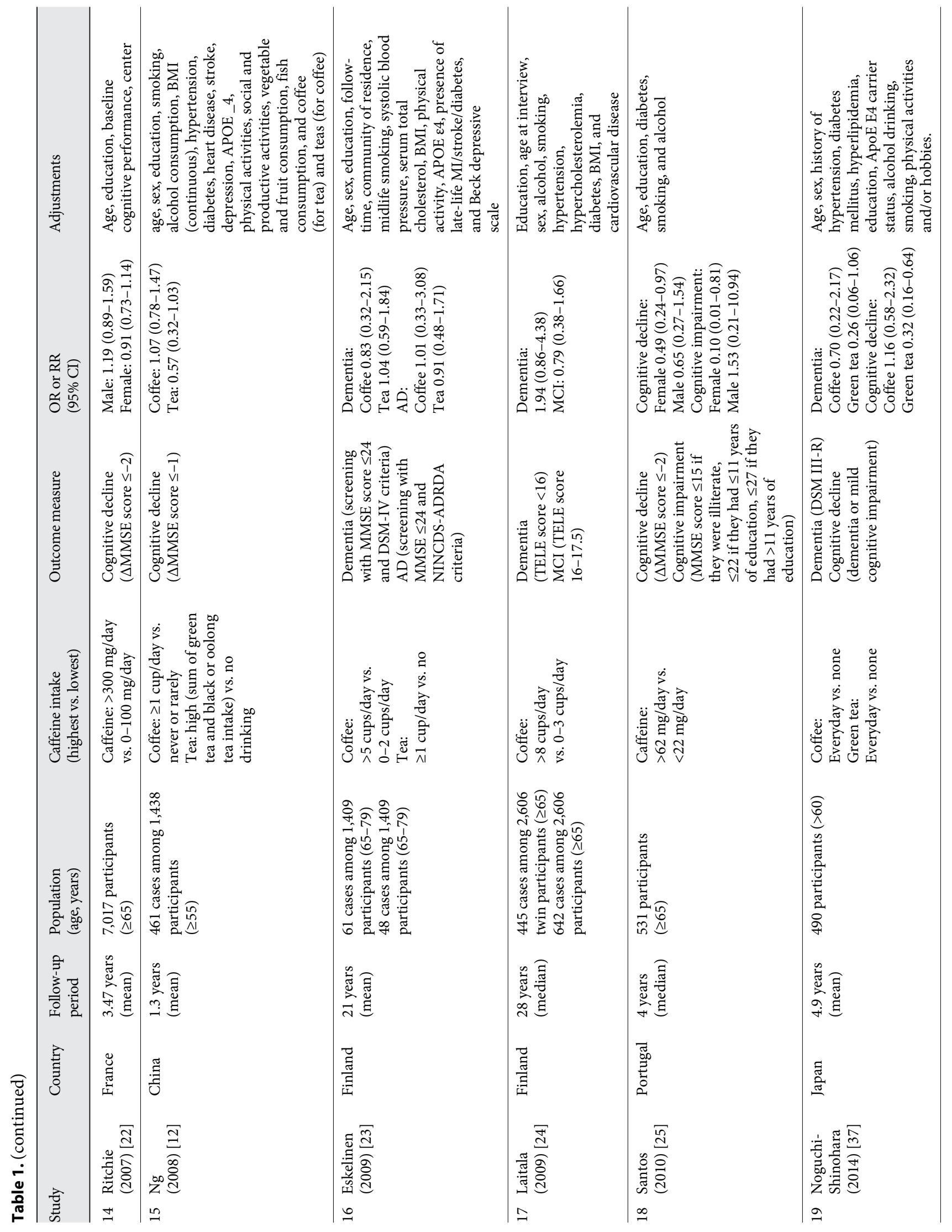



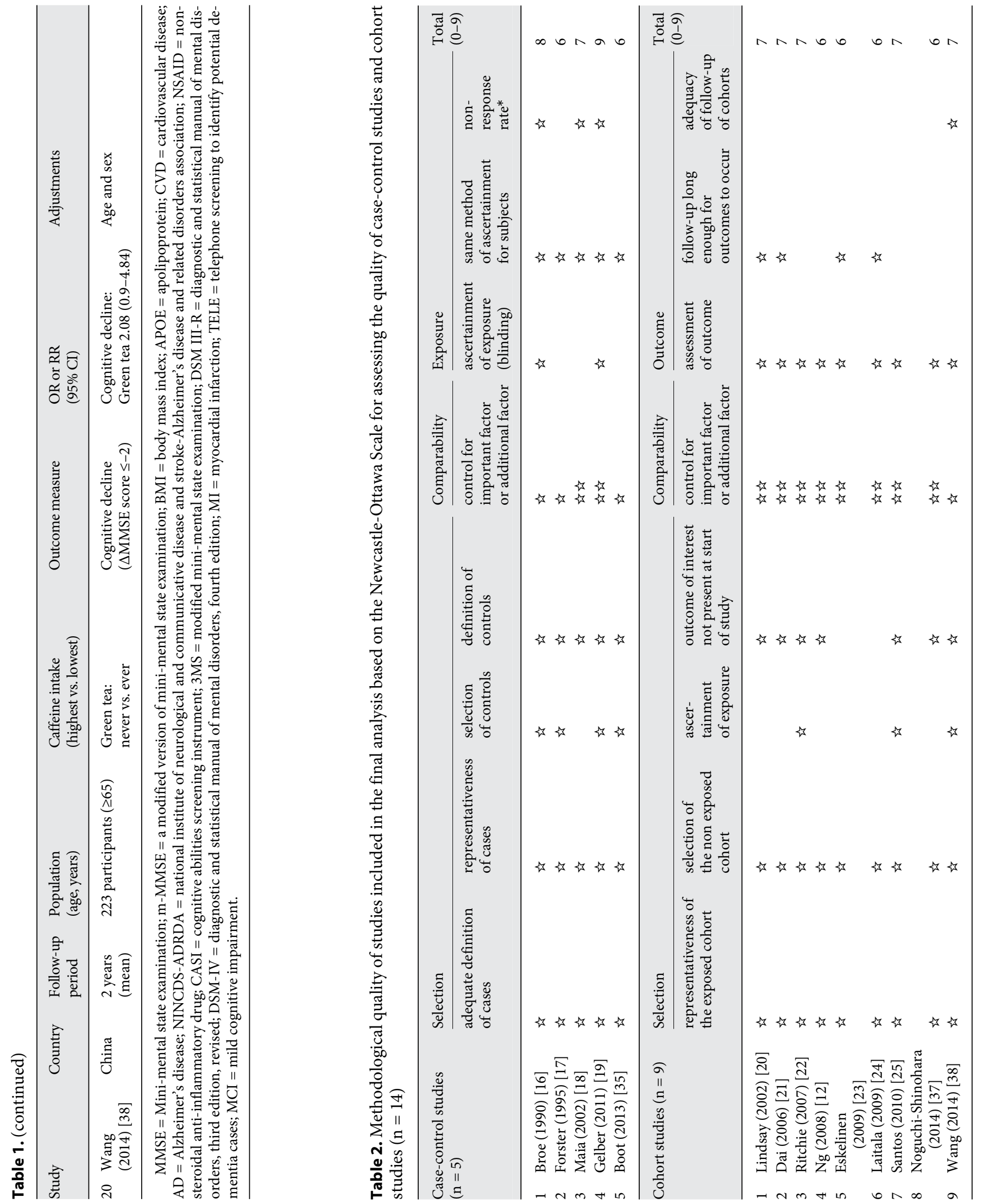
Study

\begin{tabular}{|c|c|c|c|c|}
\hline \multicolumn{5}{|l|}{ Dementia } \\
\hline 2009 Eskelinen & 1 & & $0.83(0.32,2.15)$ & 3.10 \\
\hline 2009 Laitala & & - & $1.94(0.86,4.38)$ & 3.80 \\
\hline 2011 Gelber & 1 & - & $0.29(0.14,0.57)$ & 5.81 \\
\hline 2013 Boot & 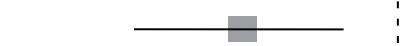 & & $1.12(0.66,1.91)$ & 4.49 \\
\hline 2014 Noquchi-shinohara & 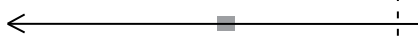 & & $0.26(0.06,1.06)$ & 1.67 \\
\hline Subtotal $\left(1^{2}=75.7 \%\right)$ & & $\longrightarrow$ & $0.72(0.34,1.51)$ & 18.87 \\
\hline \multicolumn{5}{|l|}{ Alzheimer's disease } \\
\hline 1990 Broe & $\square$ & - & $0.65(0.37,1.13)$ & 5.58 \\
\hline 1995 Forster & & + & $1.40(0.81,2.63)$ & 5.33 \\
\hline 2002 Lindsay & & & $0.69(0.50,0.96)$ & 7.70 \\
\hline 2002 Maia & & & $0.40(0.25,0.67)$ & 6.15 \\
\hline 2006 Dai & & 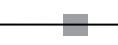 & $1.70(0.67,4.33)$ & 3.19 \\
\hline Subtotal $\left(I^{2}=71.0 \%\right)$ & & & $0.78(0.50,1.22)$ & 27.96 \\
\hline \multicolumn{5}{|l|}{ Cognitive impairment } \\
\hline 2006 Kuriyama & & & $1.03(0.59,1.80)$ & 5.59 \\
\hline 2009 Huang & & & $0.74(0.38,1.47)$ & 4.67 \\
\hline 2009 Nurk & & & $0.95(0.68,1.33)$ & 7.62 \\
\hline $2011 \mathrm{Wu}$ & + & & $0.51(0.31,0.83)$ & 6.15 \\
\hline 2013 Mashal & & & $0.74(0.30,1.60)$ & 3.67 \\
\hline Subtotal $\left(I^{2}=21.3 \%\right)$ & & & $0.79(0.61,1.04)$ & 27.69 \\
\hline \multicolumn{5}{|l|}{ Cognitive decline } \\
\hline 2007 Ritchie & & & $1.02(0.79,1.33)$ & 8.29 \\
\hline $2008 \mathrm{Ng}$ & & & $1.07(0.78,1.47)$ & 7.79 \\
\hline 2010 Santos & + & & $0.55(0.32,0.94)$ & 5.75 \\
\hline 2014 Wang & & te & $2.08(0.90,4.84)$ & 3.65 \\
\hline Subtotal $\left(I^{2}=61.7 \%\right)$ & & & $0.99(0.70,1.39)$ & 25.48 \\
\hline Overall $\left(I^{2}=63.2 \%\right)$ & & & & 100.00 \\
\hline
\end{tabular}

Fig. 2. Association between caffeine intake and cognitive disorders in the random-effects meta-analysis of epidemiological studies by type of outcomes.

Fig. 3. Begg's funnel plot and Egger's test

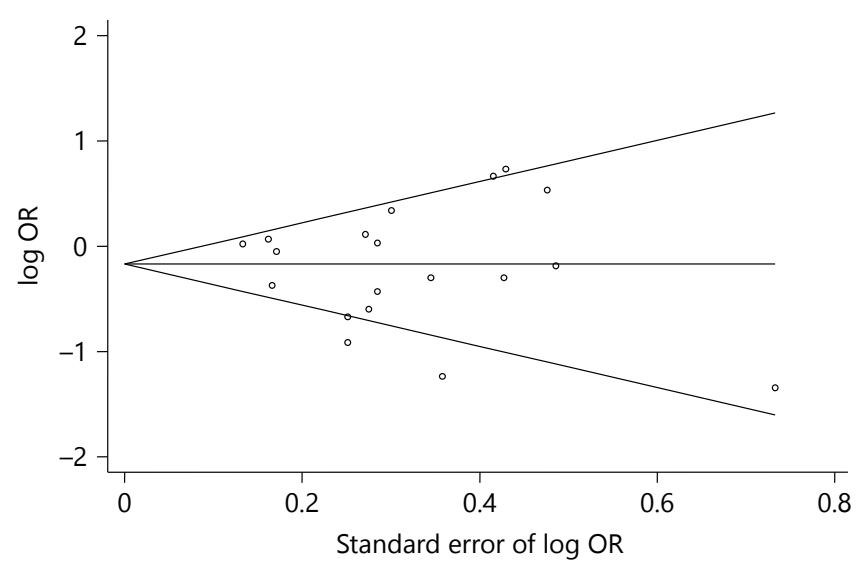

for identifying publication bias $(n=19)$.

Meta-Analysis of Caffeine Intake and Cognitive Disorders
Neuroepidemiology 2015;44:51-63 DOI: $10.1159 / 000371710$ 
Table 3. Association between caffeine intake from coffee or tea and the risk of cognitive disorders in subgroup meta-analyses

\begin{tabular}{|c|c|c|c|c|}
\hline Category & No. of studies [reference number] & $\begin{array}{l}\text { Summary } \\
\text { OR/RR (95\% CI) }\end{array}$ & $\begin{array}{l}\text { Heterogeneity, } \\
\mathrm{I}^{2}(\%)\end{array}$ & Model used \\
\hline \multicolumn{5}{|l|}{ Caffeine source } \\
\hline Cross-sectional study & $3[11,15,36]$ & $0.70(0.50-0.98)$ & 42.0 & Fixed-Effects \\
\hline Case-control study & $2[16,19]$ & $0.82(0.55-1.24)$ & 33.4 & Fixed-Effects \\
\hline Cohort study & $5[12,20,23,24,37]$ & $0.90(0.59-1.36)$ & 60.0 & Random-Effects \\
\hline Cross-sectional study & $5[11,13-15,36]$ & $1.02(0.86-1.22)$ & 44.6 & Fixed-Effects \\
\hline Case-control study & $2[16,17]$ & $0.96(0.36-2.53)$ & 56.9 & Random-Effects \\
\hline Cohort study & $6[12,20,21,23,37,38]$ & $1.04(0.74-1.46)$ & 50.2 & Random-Effects \\
\hline \multicolumn{5}{|l|}{ Study design } \\
\hline Cross-sectional study & $6[11-15,36]$ & $-0.84(0.68-1.05)$ & 15.6 & Fixed-Effects \\
\hline Case-control study & $5[16-19,35]$ & $-0.66(0.38-1.15)$ & 79.3 & Random-Effects \\
\hline Dementia (excluding AD) & $5[19,23,24,35,37]$ & $0.72(0.34-1.51)$ & 75.7 & Random-Effects \\
\hline Alzheimer’s disease (AD) & $7[16-21,23]$ & $0.81(0.57-1.15)$ & 59.1 & Random-Effects \\
\hline Cognitive impairment & $9[11-15,19,24,25,36]$ & $0.87(0.73-1.03)$ & 0 & Fixed-Effects \\
\hline Cognitive decline & $5[12,22,25,37,38]$ & $1.01(0.84-1.20)$ & 50.0 & Fixed-Effects \\
\hline \multicolumn{5}{|l|}{ Race } \\
\hline $\begin{array}{l}\text { Asian (China, Taiwan, Japan, } \\
\text { Japanease-American, Jordan, Japan) }\end{array}$ & $9[11,12,14,15,19,21,36-38]$ & $0.94(0.78-1.14)$ & 49.8 & Fixed-Effects \\
\hline Caucasian (North America, Europe, Oceania) & $10[14,16-18,20,22-25,35]$ & $0.75(0.57-1.00)$ & 71.0 & Random-Effects \\
\hline \multicolumn{5}{|l|}{ Gender } \\
\hline Male & $5[12,13,19,22,25]$ & $1.10(0.89-1.38)$ & 0 & Fixed-Effects \\
\hline Female & $4[12,13,22,25]$ & $0.90(0.75-1.08)$ & 12.3 & Fixed-Effects \\
\hline \multicolumn{5}{|l|}{ Among trials with both study designs } \\
\hline $\operatorname{High}(\geq 7)$ & $8[16,18-22,25,38]$ & $0.82(0.60-1.13)$ & 69.7 & Random-Effects \\
\hline Low $(\leq 6)$ & $6[12,17,23,24,35,37]$ & $0.83(0.48-1.45)$ & 74.1 & Random-Effects \\
\hline \multicolumn{5}{|l|}{ Dosage of caffeine intake ${ }^{1}$} \\
\hline Lower & $6[11,19,22-25]$ & $0.98(0.81-1.19)$ & 34.2 & Fixed-Effects \\
\hline Moderate & $2[19,22]$ & $1.11(0.72-1.71)$ & 69.7 & Random-Effects \\
\hline Highest & $6[11,19,22-25]$ & $0.98(0.87-1.10)$ & 31.6 & Fixed-Effects \\
\hline \multicolumn{5}{|l|}{ Daily caffeine intake } \\
\hline Coffee & $3[12,20,37]$ & $0.77(0.48-1.24)$ & 67.7 & Random-Effects \\
\hline Tea & $7[12-14,20,21,23,37]$ & $0.90(0.76-1.07)$ & 12.8 & Fixed-Effects \\
\hline Coffee or tea & $7[12-14,20,21,23,37]$ & $0.90(0.76-1.06)$ & 33.5 & Random-Effects \\
\hline
\end{tabular}

$\mathrm{OR}=$ Odds ratio; $\mathrm{RR}=$ relative risk; $\mathrm{CI}=$ confidence interval; $\mathrm{NOS}=$ Newcastle-Ottawa Scale.

${ }^{1}$ Highest intake was defined as quintile 5, quartile 4 or tertile 3; moderate as quintile 4 or quartile 3 ; lower as quintile 2, quartile 2, or tertile 2, respectively, based on each study's categorization. 
The previous meta-analysis by Santos et al. [30] concluded that caffeine intake has an inverse association with cognitive impairment or decline. In addition, a quantitative review by Barranco Quintana in 2007 [29] showed that coffee consumption is inversely associated with the risk of AD from four observational studies. There are several hypotheses regarding the neuroprotective effect of coffee and tea. In addition to the biologic action of caffeine described in the introduction, coffee is rich in niacin, magnesium, and other antioxidant substances [43]. A main antioxidant in coffee is phenol chlorogenic acid (an ester of caffeic acid and quinic acid), which could carry neuroprotective properties against cognitive deterioration [44]. Also, some studies reported that coffee consumption lowers the risk of type 2 diabetes $[45,46]$. Because insulin may have a role in normal cognitive functioning, and it regulates amyloid precursor protein (APP) and amyloid- $\beta$ protein, insulin resistance may be associated with the pathophysiology of $\mathrm{AD}$ [46]. Besides, caffeine can act against neurodegenerative changes in the brain via positive effects on serum lipids [47, 48]. For another example, a recent observational study demonstrated that caffeine intake had a better cognitive maintenance in 2,475 elderly women with concomitant cardiovascular diseases or $\geq 3$ coronary risk factors (i.e., diabetes, hypertension, hyperlipidemia, or obesity) [49].

As for tea, some animal studies $[50,51]$ suggested that tea has protective effects on cognitive function. There are also several ingredients in tea, which might affect cognitive function. Tea cathechins as antioxidants may reduce $\beta$-amyloid generation by promoting the cleavage of APP [52]. Besides, L-theanine, which is a major amino acid uniquely found in tea leaves may have a neuroprotective effect [53].

However, unlike the previous studies, our meta-analysis showed there was no association between caffeine intake and cognitive disorders. Especially, even though there was a significant preventive effect of coffee intake in the meta-analysis of all the included studies, its preventive effect was not observed in the subgroup meta-analysis of cohort studies or case-control studies; however, it was observed in the subgroup meta-analysis of cross-sectional studies. Given that a cohort study gives a higher level of evidence than a cross-sectional study or a casecontrol study, there is no clear evidence to support a beneficial effect of caffeine intake on cognitive disorders.

Our study has several limitations. First, we considered only coffee and tea as a source of caffeine intake. Therefore, there is a limitation regarding the generalization of our findings regarding the effect of caffeine intake on the risk cognitive disorders. Second, it was hard to evaluate the ex- act amounts of caffeine intake in each study. For example, the amount of caffeine contained in a cup of coffee ranges approximately from 71 to $220 \mathrm{mg}$ according to the serving size, type of coffee bean, and preparation method [54]. In general, tea is classified into three types according to the degrees of fermentation: black tea (fully fermented), oolong tea (semi-fermented), and green tea (non-fermented). Ingredients such as total phenols, catechins, and caffeine of tea show significant variability according to those types [55]. Third, considerable heterogeneity in study designs, study outcomes, categories of caffeine intakes, and measures of cognitive disorders may preclude robust findings on this topic. For example, most studies had used very different cut-points of MMSE (ranged from 10 to 26 points) for measuring cognitive impairment. Last, our meta-analysis might create a biased measure of association in the findings because selection and recall biases are common in individual cross-sectional studies and case-control studies.

Nevertheless, the strength of our study is that we performed subgroup meta-analyses by various factors such as level of caffeine exposure, caffeine source, study design, study outcome, gender, and race of participants across studies to elicit a robust conclusion on this issue. Also, we examined a comprehensive meta-analysis including more cohort studies [37, 38], case-control studies [17, 19, 35] and cross-sectional studies $[11,13-15,36]$ than the previous one.

\section{Conclusion}

In sum, our meta-analysis of observational epidemiological studies suggests that there is no association between caffeine intake from coffee or tea and the risk of cognitive disorders. Our findings should be confirmed by further large prospective cohort studies or if possible, studies with a higher level of evidence such as randomized controlled trials.

\section{Disclosure Statement}

The authors have nothing to disclose.

References

1 Swaminathan N: How to save your brain. Psychol Today 2012;45:74-79.

-2 Patterson C, Feightner JW, Garcia A, Hsiung GY, MacKnight C, Sadovnick AD: Diagnosis and treatment of dementia: 1 . Risk assessment and primary prevention of Alzheimer disease. CMAJ 2008;178:548-556. 
3 Fratiglioni L, Mangialasche F, Qiu C: Brain 15 Wu MS, Lan TH, Chen CM, Chiu HC, Lan aging: lessons from community studies. Nutr Rev 2010;68(suppl 2):S119-S127.

-4 Anstey KJ, von Sanden C, Salim A, O'Kearney $\mathrm{R}$ : Smoking as a risk factor for dementia and cognitive decline: a meta-analysis of prospective studies. Am J Epidemiol 2007; 166:367378.

5 Cassilhas RC, Viana VA, Grassmann V, Santos RT, Santos RF, Tufik S, Mello MT: The impact of resistance exercise on the cognitive function of the elderly. Med Sci Sports Exerc 2007;39:1401-1407.

66 Gillette Guyonnet S, Abellan Van Kan G, Andrieu S, Barberger Gateau P, Berr C, Bonnefoy M, Dartigues JF, de Groot L, Ferry M, Galan P, Hercberg S, Jeandel C, Morris MC, Nourhashemi F, Payette H, Poulain JP, Portet F, Roussel AM, Ritz P, Rolland Y, Vellas B: IANA task force on nutrition and cognitive decline with aging. J Nutr Health Aging 2007; 11:132-152.

7 Heckman MA, Weil J, Gonzalez de Mejia E: Caffeine (1, 3, 7-trimethylxanthine) in foods: a comprehensive review on consumption, functionality, safety, and regulatory matters. J Food Sci 2010;75:R77-R87.

8 Arendash GW, Mori T, Cao C, Mamcarz M, Runfeldt M, Dickson A, Rezai-Zadeh K, Tane J, Citron BA, Lin X, Echeverria V, Potter H: Caffeine reverses cognitive impairment and decreases brain amyloid-beta levels in aged Alzheimer's disease mice. J Alzheimers Dis 2009; 17:661-680.

$\checkmark 9$ Arendash GW, Schleif W, Rezai-Zadeh K, Jackson EK, Zacharia LC, Cracchiolo JR, Shippy D, Tan J: Caffeine protects Alzheimer's mice against cognitive impairment and reduces brain beta-amyloid production. Neuroscience 2006;142:941-952.

10 Dall'Igna OP, Fett P, Gomes MW, Souza DO, Cunha RA, Lara DR: Caffeine and adenosine $\mathrm{a}(2 \mathrm{a})$ receptor antagonists prevent beta-amyloid (25-35)-induced cognitive deficits in mice. Exp Neurol 2007;203:241-245.

$\checkmark 11$ Kuriyama S, Hozawa A, Ohmori K, Shimazu T, Matsui T, Ebihara S, Awata S, Nagatomi R, Arai H, Tsuji I: Green tea consumption and cognitive function: a cross-sectional study from the Tsurugaya project 1 . Am J Clin Nut 2006;83:355-361.

$\checkmark 12$ Ng TP, Feng L, Niti M, Kua EH, Yap KB: Tea consumption and cognitive impairment and decline in older Chinese adults. Am J Clin Nutr 2008;88:224-231.

-13 Huang CQ, Dong BR, Zhang YL, Wu HM, Liu QX: Association of cognitive impairment with smoking, alcohol consumption, tea consumption, and exercise among Chinese nonagenarians/centenarians. Cogn Behav Neurol 2009;22:190-196.

14 Nurk E, Refsum H, Drevon CA, Tell GS, Nygaard HA, Engedal K, Smith AD: Intake of flavonoid-rich wine, tea, and chocolate by elderly men and women is associated with better cognitive test performance. J Nutr 2009; 139:120-127. TY: Socio-demographic and health-related factors associated with cognitive impairment in the elderly in Taiwan. BMC Public Health 2011;11:22.

16 Broe GA, Henderson AS, Creasey H, McCusker E, Korten AE, Jorm AF, Longley W, Anthony JC: A case-control study of Alzheimer's disease in Australia. Neurology 1990;40:1698-1707.

17 Forster DP, Newens AJ, Kay DW, Edwardson JA: Risk factors in clinically diagnosed presenile dementia of the Alzheimer type: a case-control study in northern England. J Epidemiol Community Health 1995;49:253258.

18 Maia L, de Mendonca A: Does caffeine intake protect from Alzheimer's disease? Eur J Neurol 2002;9:377-382.

19 Gelber RP, Petrovitch H, Masaki KH, Ross GW, White LR: Coffee intake in midlife and risk of dementia and its neuropathologic correlates. J Alzheimers Dis 2011;23:607615.

20 Lindsay J, Laurin D, Verreault R, Hebert R, Helliwell B, Hill GB, McDowell I: Risk factors for Alzheimer's disease: a prospective analysis from the Canadian study of health and aging. Am J Epidemiol 2002;156:445-453.

21 Dai Q, Borenstein AR, Wu Y, Jackson JC, Larson EB: Fruit and vegetable juices and $\mathrm{Al}-$ zheimer's disease: the Kame project. Am J Med 2006;119:751-759.

22 Ritchie K, Carriere I, de Mendonca A, Portet F, Dartigues JF, Rouaud O, Barberger-Gateau $\mathrm{P}$, Ancelin ML: The neuroprotective effects of caffeine: a prospective population study (the three city study). Neurology 2007;69:536545.

23 Eskelinen $\mathrm{MH}$, Ngandu T, Tuomilehto J, Soininen H, Kivipelto M: Midlife coffee and tea drinking and the risk of late-life dementia: a population-based CAIDE study. J Alzheimers Dis 2009;16:85-91.

24 Laitala VS, Kaprio J, Koskenvuo M, Raiha I, Rinne JO, Silventoinen K: Coffee drinking in middle age is not associated with cognitive performance in old age. Am J Clin Nutr 2009; 90:640-646.

25 Santos C, Lunet N, Azevedo A, de Mendonca A, Ritchie K, Barros H: Caffeine intake is associated with a lower risk of cognitive decline: a cohort study from Portugal. J Alzheimers Dis 2010;20(suppl 1):S175-S185.

-26 Beydoun MA, Beydoun HA, Gamaldo AA, Teel A, Zonderman AB, Wang Y: Epidemiologic studies of modifiable factors associated with cognition and dementia: systematic review and meta-analysis. BMC Public Health 2014;14:643.

27 Di Marco LY, Marzo A, Munoz-Ruiz M, Ikram MA, Kivipelto M, Ruefenacht D, Venneri A, Soininen H, Wanke I, Ventikos YA, Frangi AF: Modifiable lifestyle factors in dementia: a systematic review of longitudinal observational cohort studies. J Alzheimers Dis 2014;42:119-135.
28 Crichton GE, Bryan J, Murphy KJ: Dietary antioxidants, cognitive function and dementia a systematic review. Plant Foods Hum Nutr 2013;68:279-292.

-29 Barranco Quintana JL, Allam MF, Serrano Del Castillo A, Fernandez-Crehuet Navajas R: Alzheimer's disease and coffee: a quantitative review. Neurol Res 2007;29:91-95.

30 Santos C, Costa J, Santos J, Vaz-Carneiro A, Lunet N: Caffeine intake and dementia: systematic review and meta-analysis. J Alzheimers Dis 2010;20(suppl 1):S187-S204.

31 Wells GA, Shea B, O'Connell D, Peterson J, Welch V, Losos M, Tugwell P: The Newcastle-Ottawa Scale (NOS) for assessing the quality of nonrandomised studies in metaanalysis.

32 Higgins JP, Thompson SG: Quantifying heterogeneity in a meta-analysis. Stat Med 2002; 21:1539-1558.

33 Begg CB, Mazumdar M: Operating characteristics of a rank correlation test for publication bias. Biometrics 1994;50:1088-1101.

-34 Egger M, Davey Smith G, Schneider M, Minder C: Bias in meta-analysis detected by a simple, graphical test. BMJ 1997;315:629-634.

35 Boot BP, Orr CF, Ahlskog JE, Ferman TJ, Roberts R, Pankratz VS, Dickson DW, Parisi J, Aakre JA, Geda YE, Knopman DS, Petersen RC, Boeve BF: Risk factors for dementia with Lewy bodies: a case-control study. Neurology 2013;81:833-840.

-36 Mashal RH: Hyperhomocysteinemia, lifestyle factors and cognitive impairment in healthy older subjects in Jordan. Pak J Nutr 2013;12: 71-79.

37 Noguchi-Shinohara M, Yuki S, Dohmoto C, Ikeda Y, Samuraki M, Iwasa K, Yokogawa M, Asai K, Komai K, Nakamura H, Yamada M: Consumption of green tea, but not black tea or coffee, is associated with reduced risk of cognitive decline. PLoS One 2014; 9:e96013.

38 Wang G, Tang HD, Zhuang JP, Xu XH, Liu LH, Li B, Wang LL, Xu ZM, Cheng Q, Chen SD: Risk factors for cognitive decline in elderly people: findings from the two-year followup study in a Shanghai urban community. J Alzheimers Dis 2014;39:891-897.

39 DSM-IV, APATFo: Diagnostic and statistical manual of mental disorders: DSM-IV. Amer Psychiatric Pub Inc, 1994.

40 Gatz M, Reynolds C, Nikolic J, Lowe B, Karel $\mathrm{M}$, Pedersen N: An empirical test of telephone screening to identify potential dementia cases. Int Psychogeriatr 1995;7:429-438.

41 McKhann G, Drachman D, Folstein M, Katzman R, Price D, Stadlan EM: Clinical diagnosis of Alzheimer's disease: report of the NINCDS-ADRDA work group under the auspices of department of health and human services task force on Alzheimer's disease. Neurology 1984;34:939-944.

42 Folstein MF, Folstein SE, McHugh PR: 'Minimental state'. A practical method for grading the cognitive state of patients for the clinician. J Psychiatr Res 1975;12:189-198. 
43 Ranheim T, Halvorsen B: Coffee consumption and human health - beneficial or detrimental? - mechanisms for effects of coffee consumption on different risk factors for cardiovascular disease and type 2 diabetes mellitus. Mol Nutr Food Res 2005;49:274-284.

-44 Svilaas A, Sakhi AK, Andersen LF, Svilaas T, Strom EC, Jacobs DR Jr, Ose L, Blomhoff R: Intakes of antioxidants in coffee, wine, and vegetables are correlated with plasma carotenoids in humans. J Nutr 2004;134:562-567.

45 Tuomilehto J, Hu G, Bidel S, Lindstrom J, Jousilahti P: Coffee consumption and risk of type 2 diabetes mellitus among middle-aged Finnish men and women. JAMA 2004;291: 1213-1219.

46 Biessels GJ: Caffeine, diabetes, cognition, and dementia. J Alzheimers Dis 2010;20(suppl 1):S143-S150.

-47 Du Y, Melchert HU, Knopf H, Braemer-Hauth M, Gerding B, Pabel E: Association of serum caffeine concentrations with blood lipids in caffeine-drug users and nonusers - results of German national health surveys from 1984 to 1999. Eur J Epidemiol 2005;20:311-316.
48 Tuomilehto J, Tanskanen A, Pietinen P, Aro A, Salonen JT, Happonen P, Nissinen A, Puska $\mathrm{P}$ : Coffee consumption is correlated with serum cholesterol in middle-aged Finnish men and women. J Epidemiol Community Health 1987;41:237-242.

49 Vercambre MN, Berr C, Ritchie K, Kang JH: Caffeine and cognitive decline in elderly women at high vascular risk. J Alzheimers Dis 2013;35:413-421.

50 Unno K, Takabayashi F, Kishido T, Oku N: Suppressive effect of green tea catechins on morphologic and functional regression of the brain in aged mice with accelerated senescence (SAMP10). Exp Gerontol 2004;39: 1027-1034.
51 Haque AM, Hashimoto M, Katakura M, Tanabe Y, Hara Y, Shido O: Long-term administration of green tea catechins improves spatial cognition learning ability in rats. J Nutr 2006;136:1043-1047.

52 Rezai-Zadeh K, Shytle D, Sun N, Mori T, Hou $\mathrm{H}$, Jeanniton D, Ehrhart J, Townsend K, Zeng J, Morgan D, Hardy J, Town T, Tan J: Green tea epigallocatechin-3-gallate (EGCG) modulates amyloid precursor protein cleavage and reduces cerebral amyloidosis in Alzheimer transgenic mice. J Neurosci 2005;25:88078814.

53 Nathan PJ, Lu K, Gray M, Oliver C: The neuropharmacology of L-theanine(N-ethyl-Lglutamine): a possible neuroprotective and cognitive enhancing agent. J Herb Pharmacother 2006;6:21-30.

54 Nehlig A: Are we dependent upon coffee and caffeine? A review on human and animal data. Neurosci Biobehav Rev 1999;23:563-576.

55 Khokhar S, Magnusdottir SG: Total phenol, catechin, and caffeine contents of teas commonly consumed in the United Kingdom. J Agric Food Chem 2002;50:565-570. 